\title{
PENGARUH STRES KERJA, KEPUASAN KERJA DAN KOMPENSASI FINANSIAL TERHADAP KINERJA KARYAWAN
}

\author{
Putu Bagoes Dharmayasa ${ }^{1}$ \\ I Gusti Ayu Dewi Adnyani² \\ ${ }^{1,2}$ Fakultas Ekonomi dan Bisnis Universitas Udayana, Bali, Indonesia \\ email: bdharmayasa07@gmail.com
}

\begin{abstract}
ABSTRAK
Tujuan dari penelitian ini adalah untuk menganalisis pengaruh stres kerja terhadap kinerja karyawan, untuk menganalisis pengaruh kepuasan kerja terhadap kinerja karyawan dan untuk menganalis pengaruh kompensasi finansial terhadap kinerja karyawan. Populasi dari penelitian ini adalah seluruh karyawan outdoor yang berhubungan langsung dengan tamu sebanyak 103 orang dan seluruh populasi dijadikan sebagai sampel penelitian dengan teknik sampel jenuh (saturated sampling) yaitu teknik sensus. Analisis data dalam penelitian ini yaitu analisis regresi linier berganda. Hasil dari penelitian ini menunjukan bahwa (1) Stres kerja berpengaruh negatif terhadap Kinerja karyawan, (2) Kepuasan kerja berpengaruh positif terhadap Kinerja karyawan dan (3) Kompensasi finansial berpengaruh positif terhadap Kinerja karyawan. Sebaiknya pihak manajemen perusahaan hendaknya tidak memberikan tanggung jawab yang tidak sesuai dengan jabatan serta deskripsi pekerjaan yang diemban karyawan, merancang lingkungan kerja yang mendukung serta menerapkan kebijakan agar karyawan antar satu dengan yang lain dapat memberikan dukungan serta hendaknya memberikan insentif yang sesuai dengan kinerja karyawan.
\end{abstract}

Kata kunci: stres kerja, kepuasan kerja, kompensasi finansial, kinerja karyawan.

\begin{abstract}
The purpose of this study is to analyze the effect of work stress on employee performance, to analyze the effect of job satisfaction on employee performance and to analyze the effect of financial compensation on employee performance. The population of this study is all outdoor employees who deal directly with guests as many as 103 people and the entire population is used as a research sample with saturated sampling technique (census technique). Data analysis in this research is multiple linear regression analysis. The results of this study indicate that (1) Job stress has a negative effect on employee performance, (2) Job satisfaction has a positive effect on employee performance and (3) Financial compensation has a positive effect on employee performance. The company management should not give responsibilities that are not in accordance with the position and job descriptions carried out by employees, design a supportive work environment and implement policies so that employees between one another can provide support and should provide incentives in accordance with employee performance.
\end{abstract}

Keywords: job stress, job satisfaction, financial compensation, employee performance. 


\section{PENDAHULUAN}

PT. Siwa Sempurna Dive and Watersport adalah perusahaan jasa yang bergerak di bidang wisata bahari, didirikan pada tahun 2000 oleh Bapak Putu Suwitra. Berlokasi di objek wisata Pantai Tanjung Benoa Jln. Pratama Tanjung Benoa-Nusa Dua Bali, persisnya berada di sebelah utara kawasan Nusa Dua berjarak 20 menit dari Bandara Internasional I Gusti Ngurah Rai, dan termasuk ke dalam wilayah administratif Kecamatan Kuta Selatan, Kabupaten Badung. Watersport ini banyak dikunjungi oleh tamu mancanegara yang menggunakan jasa perusahaan Travel Agent dari negara asalnya yang dominan berasal dari India, China, Hongkong, China Taipe, Jepang, Korea Selatan, Singapore, Malaysia, Australia dan berbagai tamu yang berasal dari negara-negara Eropa maupun tamu domestik.

Perusahaan ini juga menyediakan berbagai wahana wisata bahari seperti Parasailing, Banana boat, Jet ski, Fly fish, Tubing ride, Parasailing adventure, Fly board, Glass bottom boat + Turtle island, Snorkeling, Wake board, Water skiing, Diving, Sea walker, Dolphin tours, Coral fishing and Trowling fishing dan semua aktivitas tersebut telah dilindungi oleh asuransi serta bebas biaya transportasi bagi tamu yang menginap pada area Nusa Dua, Jimbaran, Kuta, Sanur dan sekitarnya.

Menurut Suparyadi (2015:271), dalam Manajemen Sumber Daya Manusia, hubungan antara organisasi dengan karyawan merupakan suatu kerjasama dalam kontrak psikologis, yaitu bahwa masing-masing pihak memiliki hak dan kewajiban yang telah disepakati bersama. Yusnimar \& Mahdani (2015), menyatakan bahwa keberhasilan suatu organisasi dipengaruhi oleh kinerja karyawan, untuk itu setiap perusahaan harus berusaha meningkatkan kinerja karyawan dalam mencapai tujuan organisasi. Namun belakangan ini dalam kurun waktu 6 (enam) bulan terakhir terdapat beberapa masalah yang dialami oleh perusahaan, salah satu diantaranya yaitu permasalahan kinerja karyawan yang ditandai dengan complain dari tamu yang berkunjung baik secara langsung ke manajemen perusahaan atau melalui situs TripAdvisor maupun Google Review dengan cara memberikan rating rendah dan juga memberikan ulasan yang buruk. Pengumpulan data dan proses mencari sumber data terkait dengan kinerja karyawan yang ada di PT. Siwa Sempurna Dive and Watersport, peneliti melakukan wawancara dan observasi bersama dengan beberapa tamu yang dominan berasal dari India.

Hasil wawancara dan observasi dari beberapa tamu yaitu complaint mengenai staf yang melayani pada saat bermain parasailing, tidak menjelaskan secara detail cara permainan tersebut, sikap staf yang cenderung kasar saat menjelaskan bagaiman cara bermain jetski dan juga mendapati Compact Disc yang dibeli tidak dapat terbuka di perangkatnya serta para tamu terlambat dijemput oleh sopir kantor yang seharusnya pada schedule jam 09.00 dan baru dijemput pada jam 10.30, staff guest relation yang menurut mereka memaksa untuk memilih suatu permainan. Berikut data penilaian beberapa watersport yang ada di wilayah Tanjung Benoa Bali pada situs Google review dan TripAdvisor yaitu: 
Tabel 1.

Rating watersport pada situs Google review di Tanjung Benoa Tahun 2019

\begin{tabular}{clc}
\hline No & \multicolumn{1}{c}{ Nama Watersport } & Nilai \\
\hline 1 & Batara Dive and Watersport & 4,3 \\
2 & BMR Dive and Watersport & 4,2 \\
3 & Rai Watersport and Restaurant & 4,2 \\
4 & NBC Dive and Watersport & 4,1 \\
5 & Bali Dolphin Watersport & 4,0 \\
6 & Siwa Sempurna Dive and Watersport & 3,9 \\
\hline
\end{tabular}

Sumber: Google (2019)

Berdasarkan Tabel 1. dapat dilihat bahwa nilai tertinggi yaitu Batara Dive and Watersport dengan rating 4,3 yang berarti memiliki complain terendah, sedangkan jumlah nilai terendah Siwa Sempurna Dive and Watersport dengan rating 3,9 yang memiliki arti bahwa terdapat paling banyak complain dari para tamu di Google Review.

Tabel 2.

Rating watersport pada situs TripAdvisor di Tanjung Benoa Tahun 2019

\begin{tabular}{clc}
\hline No & \multicolumn{1}{c}{ Nama Watersport } & Nilai \\
\hline 1 & Wibisana Dive and Watersport & 4,0 \\
2 & Rai Watersport and Restaurant & 3,5 \\
3 & Bali Dolphin Watersport & 3,0 \\
4 & BMR Dive and Watersport & 3,0 \\
5 & NBC Dive and Watersport & 2,0 \\
6 & Siwa Sempurna Dive and Watersport & 1,5 \\
\hline
\end{tabular}

Sumber: Tripadvisor (2019)

Berdasarkan Tabel 2. dapat dilihat bahwa nilai tertinggi yaitu Wibisana Dive and Watersport dengan rating 4,0 yang berarti memiliki complain terendah sedangkan nilai terendah yaitu Siwa Sempurna Dive and Watersport dengan rating 1,5 yang memiliki arti bahwa terdapat paling banyak complain dari para tamu di TripAdvisor.

Sementara itu hasil wawancara singkat peneliti dengan pihak atasan dari perusahaan, mendapatkan bahwa memang terdapat masalah pada kinerja karyawan perusahaan yang ditandai dengan complain dari para tamu akan service yang diberikan oleh karyawan dan juga banyaknya guide mengeluhkan client nya tidak mendapat service yang baik serta merasa komisi nya untuk mendatangkan tamu dipotong dan tidak mendapatkan dalam jumlah yang semestinya.

Perlunya pengelolaan sumber daya manusia yang baik dalam industri pariwisata tentunya adalah hal yang sangat penting, agar para karyawan dapat memberikan pelayanan terbaik. Mondy \& Noe (2013) mendefinisikan manajemen sumber daya manusia sebagai pemanfaatan sumber daya manusia untuk mencapai tujuan organisasi. Dalam meningkatkan kualitas perusahaan, elemen yang paling penting adalah sumber daya manusia yang ada di dalamnya. Dengan demikian, perusahaan harus memiliki sumber daya manusia yang berkualitas untuk mencapai tujuan tersebut sehingga dapat bertahan. Torang (2013) menyatakan kinerja adalah kuantitas dan kualitas kerja individu atau kelompok organisasi dalam melaksanakan tugas pokok dan fungsi yang diarahkan oleh standar prosedur operasi, kriteria yang 
telah ditentukan dan standar dalam organisasi. Hermawati (2012) yang juga menyebutkan bahwa kinerja adalah hasil kerja seseorang selama periode tertentu dibandingkan dengan berbagai kemungkinan, misalnya standar, target, atau kriteria lain yang telah ditentukan terlebih dahulu oleh organisasi dan telah disepakati bersama

Sumber daya manusia merupakan aset penting bagi organisasi yang dimana peran manajemen sumber daya manusia adalah untuk mempertahankan dan meningkatkan kinerja karyawan. Mangkunegara (2015:67) mengemukakan bahwa kinerja karyawan yaitu hasil kerja secara kualitas dan kuantitas yang dicapai oleh seorang pegawai dalam melaksanakan tugasnya sesuai dengan tanggung jawab yang diberikan padanya. Kinerja karyawan yang sangat rendah akan menyebabkan perusahaan mengalami kerugian yang kemudian dapat berakhir dengan penutupan perusahaan. Penting bagi setiap perusahaan untuk mempertahankan dan meningkatkan kinerja karyawan sesuai dengan tujuan yang diinginkan (Hanim, 2016).

Sebagian besar penelitian yang telah dilakukan di negara-negara yang berusaha berkembang untuk menjadi maju secara ekonomi dan sosial seperti menurut Alam \& Shah (2013), stres kerja dianggap menjadi masalah di seluruh dunia dan terus meningkat di negara-negara lain di mana industri yang berkembang pesat. Menurut Velnampy \& Aravinthan (2013) stres kerja adalah pola emosional perilaku kognitif dan reaksi psikologis terhadap aspek yang merugikan dan berbahaya dari setiap pekerjaa, organisasi kerja dan lingkungan kerja. Stres kerja juga dapat dianggap sebagai situasi emosional yang tidak menyenangkan, bahwa pengalaman karyawan ketika kebutuhan terkait perimbangan tidak dapat atau tidak berhubungan dengan pekerjaan dan kemampuan untuk mengatasinya (Halkos \& Bousinakis, 2010). Pada penelitian sebelumnya yang dilakukan oleh Harianto et al. (2008), menemukan hasil bahwa terdapat pengaruh negatif antara stres kerja dengan kinerja karyawan, sedangkan Zafar et al. (2015) menyatakan bahwa terdapat hubungan positif signifikan antara stres kerja terhadap kinerja karyawan.

Dampak negatif yang ditimbulkan oleh stres kerja dapat berupa gejala fisiologis, psikologis dan perilaku (Robbins, 2013:601). Logan \& Ganster (2005) menyatakan stres adalah reaksi yang tidak diinginkan ketika seorang mengalami tekanan berat atau jenis lain dari tuntutan pekerjaan yang ditempatkan di atas pekerjaan mereka, banyak faktor kunci seperti lingkungan kerja, dukungan manajemen, beban kerja dan lainya dalam menentukan stres kerja dan efeknya pada kesehatan fisik maupun mental karyawan. Stres kerja telah menjadi salah satu yang paling populer sebagai "penyakit akibat kerja" dari abad ke abad dan itu telah mempengaruhi individu secara fisik maupun psikologis, menyebabkan tekanan yang berdampak terhadap kinerja karyawan (Leka et al., 2004). Penyebab stres kerja off the job antara lain : faktor keuangan, keluarga, dan masyarakat (Charisma et al., 2014). Artinya stres muncul pada saat karyawan tidak mampu memenuhi apa yang menjadi tuntutan-tuntutan pekerjaan.

Berdasarkan pada laporan, ambiguitas peran, perubahan organisasi, tuntutan pekerjaan, intimidasi dan kekerasan adalah beberapa faktor stres yang umum terjadi di tempat kerja saat ini dan penting bagi perusahaan untuk meningkatkan kepuasan kerja karyawan yang berdampak pada kinerja. Stres kerja ditimbulkan dari berbagai 
hal yang membuat karyawan merasa kurang nyaman. Menurut Triatna (2015:139) "Faktor penyebab stres adalah faktor pekerjaan, faktor non-pekerjaaan, dan faktor dari pribadi seseorang." Berikut hasil observasi awal dan wawancara mengenai stress kerja, sumber data didapat dari pernyataan beberapa karyawan outdoor dari divisi GBB atau kapal. Hasil wawancara dari beberapa karyawan bahwa adanya perubahan situasi bisnis yang terkadang sepi menciptakan ketidakpastian terhadap ekonomi di pariwisata, bila kunjungan wisatawan atau tamu menurun, orang-orang menjadi semakin mencemaskan kesejahteraan mereka. Selain itu tuntutan tugas dan tekanan untuk menjalankan tugasnya secara baik dan benar, jika terjadi complaint dari tamu maka akan ditegur oleh atasan dan bahkan diberikan sanksi. Persaingan didunia kerja sangat ketat sehingga adanya permasalahan dengan rekan kerja yang menyebabkan suasana tempat kerja sangat tidak nyaman.

Kepuasan kerja karyawan memainkan peran yang sangat penting pada kinerja organisasi. Zainal et al. (2014), menyatakan bahwa kepuasan kerja adalah penilaian dari pekerja tentang seberapa jauh pekerjaannya secara keseluruhan memuaskan kebutuhanya. Hal ini penting untuk mengetahui bagaimana karyawan dapat dipertahankan melalui membuat mereka puas untuk mencapai hasil yang luar biasa. Kepuasan kerja timbul akibat cara yang ditunjukan para manajer dalam memperhatikan dan meminta pendapat serta keikutsertaan bawhannya, sehingga para pekerja merasa bahwa mereka mmerupakan bagian dari internal organisasi dari organisasinya dan merasa bahwa atasan memperhatikan mereka (Firmansah \& Santy, 2011). Kepuasan kerja adalah bagaimana orang berpikir dan merasa tentang tempat kerja mereka melalui berbagai aspek mengenai hal itu.

Kepuasan kerja adalah semua tentang perilaku yang sejauh mana orang suka atau tidak suka tempat kerja mereka. Karyawan merasa prestasi dan keberhasilan di tempat kerja merupakan kepuasan kerja. Umumnya, hal itu berdampak langsung ke produktivitas serta kesejahteraan karyawan. Kepuasan kerja mensyaratkan bahwa jika seseorang melakukan aktivitas kerja sangat baik maka upayanya harus dihargai. Sowmya \& Panchanatham (2011) menyatakan kepuasan kerja adalah suatu keadaan karyawan merasa puas terhadap pekerjaannya. Orang yang mengungkapkan kepuasaan yang tinggi dalam pekerjaannya cenderung lebih produktif, mempunyai keterlibatan yang tinggi dan kecil kemungkinannya dalam mengundurkan diri dibandingkan dengan karyawan yang merasakan kepuasaan kerja yang kurang. Hal ini dinyatakan oleh Kaliski (2007) bahwa kepuasan kerja menyiratkan kebahagiaan serta antusiasme karayawan dengan pekerjaannya dan itu adalah komponen kunci yang mengarahkan karyawan uantuk promosi, peningkatan pendapatan, pengakuan dan pencapaian tujuan-tujuan lain yang mengarah ke pemenuhan perasaan. Target dan prestasi tergantung pada kepuasan karyawan yang pada nantinya akan memberikan kontribusi bagi keberhasilan, pertumbuhan, meningkatkan produktivitas, dan meningkatkan kualitas kerja organisasi.

Hal ini sangat diperlukan bagi suatu organisasi untuk merasakaan seperti apa karyawan merasa, berpikir, dan membuat strategi yang dapat meningkatkan dedikasi dan kinerja karyawan. Penelitian sebelumnya yang dilakukan oleh Shahzad et al. (2013), mengatakan bahwa ada korelasi positif antara kepuasan kerja dan kinerja organisasi. Purnomo et al. (2013) juga menyimpulkan bahwa karyawan dengan kepuasan kerja yang tinggi akan merasa bahagia dalam pekerjaan mereka 
dan tidak mencoba untuk mengevaluasi alternatif pekerjaan lain. Meningkatkan kepuasan kerja karyawan merupakan factor yang sangat penting bagi keberhasilan suatu organisasinya.

Untuk fenomena kepuasan kerja akan dipaparkan hasil observasi awal dan wawancara dengan beberapa karyawan outdoor dari divisi GRO. Hasil wawancara dari beberapa karyawan GRO yaitu adanya ketidakpuasan karyawan mengenai oknum tamu yang sering membuat permintaan berlebih diluar paket permainan yang dibeli pada perusahaan travel agent yang digunakan, sehingga menimbulkan usaha yang lebih untuk mengatasi dan menyebabkan waktu terbuang untuk berdebat dan menyebabkan kinerja yang tidak optimal, mereka tidak puas karena selalu diperintahkan lebih sering untuk melaksanakan tugas marketing sehingga beliau tidak dapat bekerja untuk mendapatkan penghasilan tambahan selain gaji seperti tips dari para tamu. Sikap atasan yang tidak konsisten dan kurang adil dengan para karyawan sehingga banyak terjadi kecemburuan sosial diantara para karyawan yang menyebabkan lingkungan kerja tidak kondusif dan persaingan tidak sehat.

Kinerja yang rendah juga disebabkan oleh masalah kompensasi finansial dalam suatu perusahaan (Rivai, 2006:261). Kompensasi adalah semua pendapatan yang berbentuk uang, barang langsung atau tidak langsung yang diterima karyawan sebagai imbalan atas jasa yang diberikan kepada perusahaan. Khan et al. (2012) mengatakan kompensasi adalah pemberian upah yang merupakan imbalan, pembayaran untuk pelayanan yang telah diberikan oleh karyawan. Menurut Aprijon (2014) secara sederhana kompensasi merupakan sesuatu yang diterima karyawan dari perusahaan untuk balas jasa kerja mereka. Seseorang bekerja dalam suatu perusahaan untuk memperoleh imbalan atau balas jasa untuk dapat memenuhi kebutuhan hidupnya, oleh karena itu perusahaan memberikan penghargaan dengan jalan memberikan kompensasi bagi karyawannya. Omotayo et al. (2014) menyatakan kompensasi adalah penghargaan karyawan yang diterima sebagai imbalan untuk melakukan tugas organisasi. Tantowi et al. (2016) menyatakan bahwa kompensasi finansial terdiri dari (dua) bentuk yaitu: secara langsung dan tidak langsung. Kompensasi finansial langsung dapat berupa upah, agaji, bonus dan komisi, sedangkan kompensasi finansial tidak langsung dapat berupa tunjangan, dan semua balas jasa yang bersifat tetap, tetapi bukan termasuk kompensasi langsung.

Berikut hasil observasi awal dan wawancara mengenai kompensasi finansial, sumber data didapat dari pernyataan beberapa karyawan. Hasil wawancara dari beberapa karyawan yaitu kurangnya penghargaan seperti bonus untuk karyawan yang mendatangkan travel agent dan tamu untuk perusahaan. Karyawan lainnya juga menyatakan mendapatkan tunjangan hari raya yang sedikit dan gaji setiap bulan yang sering mengalami keterlambatan.

Dar et al. (2011) menyatakan bahwa stes kerja berpengaruh negatif terhadap kinerja. Hal ini menunjukkan bahwa semakin tinggi stres kerja yang dirasakan oleh karyawan, menyebabkan penurunan kinerja. Noermijati (2017) menyatakan stres kerja berpengaruh negatif signifikan terhadap kinerja karyawan. Hasil penelitian ini diperkuat oleh pernyataan Kotteeswari \& Sharief (2014) bahwa ada pengaruh negatif pada stres kerja terhadap kinerja karyawan. Adapun penelitian yang 
dilakukan oleh Warraich et al. (2014) menyatakan bahwa stress kerja berpengaruh negatif terhadap kinerja karyawan pada Universities of Karachi Pakistan.

Hasil penelitian Kanaka (2019) menunjukkan bahwa stres kerja memiliki efek negatif dan signifikan terhadap kinerja pengguna barang. Alam et al. (2015) menyatakan bahwa stres kerja berpengaruh negatif terhadap kinerja karyawan Perbankan Sektor di Khyber Pakhtunkwa Pakistan. Jehangir et al. (2011) stres kerja memiliki korelasi negatif dengan kinerja pekerjaan. Hasil penelitian Olusegun et al. (2014) juga menyatakan juga bahwa stres kerja berpengaruh negative dan signifikan terhadap kinerja karyawan. Kemudian dalam penelitian lain dengan peneliti Putra \& Rahyuda (2015) menyatakan bahwa ada efek negatif dari stres kerja terhadap kinerja. Ahmed \& Ramzan (2013) menyatakan antara stres kerja dan prestasi kerja berkorelasi negatif

$\mathrm{H}_{1}$ : Stress Kerja berpengaruh negatif terhadap Kinerja Karyawan.

Karyawan yang puas memiliki sikap positif tentang pekerjaan mereka. Beberapa penelitian mengemukakan bahwa kepuasan kerja memiliki pengaruh positif dan signifikan terhadap kinerja karyawan yang berarti bahwa rasa kepuasan kerja yang dimiliki pekerja membuat pekerja untuk meningkatkan kinerjanya (Wijayanti \& Subudi, 2014). Dinoka et al. (2014) sebelumnya telah melaporkan bahwa kepuasan kerja memiliki hubungan yang signifikan dengan kinerja kerja karyawan di berbagai sektor bisnis. Prawira \& Suwandana (2019) menyatakan bahwa kepuasan kerja berpengaruh postif dan signifikan terhadap kinerja. Shahzad et al. (2013) dalam penelitianya menyatakan ada korelasi positif antara kepuasan kerja dan kinerja organisasi. Kepuasan kerja memiliki pengaruh yang signifikan terhadap kinerja karyawan (Nazariadli, 2017). Kepuasan kerja juga memberikan pengaruh yang lebih baik kepada kinerja karyawan (Issac, 2017).

Ujianto \& Suhermin (2018) dalam penelitianya yang berjudul Effect of work stress and role conflict on job satisfaction, burn out and performance of female nurses in the sawerigading palopo public hospital menyatakan kepuasan kerja secara positif memberikan dampak pada prestasi kerja perawat perempuan di Rumah Sakit Sawerigading Palopo Umum. Ini berarti bahwa pada tingkat yang lebih tinggi kepuasan kerja akan meningkatkan kinerja pekerjaan perawat perempuan.

$\mathrm{H}_{2}$ : Kepuasan Kerja berpengaruh positif terhadap Kinerja Karyawan.

Darmawan (2018) menayatakan bahwa, variabel kompensasi finansial secara parsial berpengaruh signifikan terhadap kinerja karyawan. Etebu (2016) menyatakan terdapat pengaruh signifikan antara kompensasi finansial dengan kinerja karyawan. Hasil penelitian Fredriksz (2017) menunjukkan bahwa kompensasi finansial berpengaruh positif dan signifikan terhadap kinerja karyawan. Hal ini menunjukkan bahwa semakin tinggi kompensasi finansial yang diberikan oleh perusahaan, menyebabkan peningkatan kinerja karyawan. Baharuddin et al. (2012) menyatakan pula bahwa kompensasi memiliki pengaruh positif signfikan terhadap kinerja.

Sementara itu, Nurjahjani (2012) di penelitiannya yang berjudul "pengaruh imbalan finansial terhadap prestasi kerja" menyatakan bahwa kompensasi finansial berpengaruh signifikan terhadap kinerja karyawan departemen pemasaran Jiwa Asih Bumi Jaya Branch Malang. Kompensasi finansial juga berpengaruh positif 
dan signifikan terhadap kinerja karyawan (Siagian et al., 2018). Hal ini didukung dari penelitian Siregar (2011) dan Muguongo et al. (2015) yang menyatakan bahwa kompensasi finansial berpengaruh positif dansignifikan terhadap kepuasan kerja. Tingkir (2015) menyatakan kompensasi finansial memiliki pengaruh signifikan terhadap kinerja.

$\mathrm{H}_{3}$ : Kompensasi Finansial berpengaruh positif dan signifikan terhadap Kinerja Karyawan.

\section{METODE PENELITIAN}

Lokasi penelitian ini dilakukan di PT. Siwa Sempurna Dive and Watersport yang beralamat di Jalan Pratama Tanjung Benoa-Nusa Dua Bali. Penelitian ini dilakukan pada PT. Siwa Sempurna Dive and Watersport karena peneliti tertarik untuk mengangkat permasalahan yang terjadi yaitu complain dan peneliti juga berasal dari keluarga yang berkecimpung di dunia pariwisata khususnya di daerah Tanjung Benoa.

Dalam penelitian ini, populasi yang dimaksudkan adalah seluruh karyawan Outdoor (yang berhubungan langsung dengan tamu) PT. Siwa Sempurna Dive and Watersport.

Tabel 3.

Jumlah karyawan PT. Siwa Sempurna Dive and Watersport

\begin{tabular}{ccc}
\hline No & Divisi & Jumlah Karyawan \\
\hline 1 & PS Adventure & 17 \\
2 & Jet Ski & 6 \\
3 & Parasailing & 9 \\
4 & Dive \& Sea Walker & 14 \\
5 & Sopir Mobil & 4 \\
6 & CD Room & 2 \\
7 & G.R.O Pria & 19 \\
8 & G.R.O Wanita & 19 \\
9 & GBB/Kapal & 15 \\
& TOTAL & 103 \\
\hline
\end{tabular}

Sumber: Data diolah, 2019

Teknik sampling yang digunakan dalam penelitian ini adalah sampel jenuh (saturated sampling), yaitu teknik sensus, dengan demikian seluruh anggota populasi sebagai sampel penelitian.

Uji hipotesis melalui analisis regresi linier berganda dilakukan untuk mengetahui ketergantungan variabel terikat dengan satu atau lebih variabel bebas. Analisis regresi linier berganda digunakan karena mampu menginterpretasikan hubungan linier antara stres kerja, kepuasan kerja, kompensasi finansial dan kinerja karyawan. Metode ini diuji dengan menggunakan sistem komputer berupa SPPS. Adapun rumus model regresi linier berganda (Wirawan, 2002:293) yang digunakan sebagai berikut.

$Y=\alpha+\beta_{1} X_{1}+\beta_{2} X_{2}+\beta_{3} X_{3} \varepsilon$

Keterangan :

$\begin{array}{ll}\mathrm{Y} & =\text { Kinerja Karyawan } \\ \mathrm{X}_{1} & =\text { Stres Kerja }\end{array}$ 




\section{HASIL DAN PEMBAHASAN}

Uji validitas dilakukan dengan cara menghitung korelasi antara skor masingmasing pertanyaan pada kuisioner. Jika koefisien korelasi positif dan lebih besar dari 0,361 maka indikator dapat dikatakan valid.

Tabel 4.

Rekapitulasi Hasil Uji Validitas Instrumen Penelitian

\begin{tabular}{|c|c|c|c|c|}
\hline Variabel & Indikator & R hitung & $\mathbf{R}$ tabel & Keterangan \\
\hline \multirow{6}{*}{ Stres Kerja $\left(\mathrm{X}_{1}\right)$} & $\mathrm{X}_{1.1}$ & 0,777 & 0,30 & Valid \\
\hline & $\mathrm{X}_{1.2}$ & 0,822 & 0,30 & Valid \\
\hline & $\mathrm{X}_{1.3}$ & 0,884 & 0,30 & Valid \\
\hline & $\mathrm{X}_{1.4}$ & 0,926 & 0,30 & Valid \\
\hline & $\mathrm{X}_{1.5}$ & 0,847 & 0,30 & Valid \\
\hline & $\mathrm{X}_{2.1}$ & 0,729 & 0,30 & Valid \\
\hline \multirow{3}{*}{ Kepuasan Kerja $\left(\mathrm{X}_{2}\right)$} & $\mathrm{X}_{2.2}$ & 0,832 & 0,30 & Valid \\
\hline & $\mathrm{X}_{2.3}$ & 0,848 & 0,30 & Valid \\
\hline & $\mathrm{X}_{2.4}$ & 0,937 & 0,30 & Valid \\
\hline \multirow{5}{*}{$\begin{array}{l}\text { Kompensasi Finansial } \\
\qquad\left(\mathrm{X}_{3}\right)\end{array}$} & $\mathrm{X}_{2.5}$ & 0,769 & 0,30 & Valid \\
\hline & $\mathrm{X}_{3.1}$ & 0,764 & 0,30 & Valid \\
\hline & $\mathrm{X}_{3.2}$ & 0,848 & 0,30 & Valid \\
\hline & $\mathrm{X}_{3.3}$ & 0,858 & 0,30 & Valid \\
\hline & $\mathrm{X}_{3.4}$ & 0,958 & 0,30 & Valid \\
\hline \multirow{8}{*}{ Kinerja Karyawan (Y) } & $Y_{.1}$ & 0,808 & 0,30 & Valid \\
\hline & $\mathrm{Y}_{.2}$ & 0,779 & 0,30 & Valid \\
\hline & $Y_{.3}$ & 0,899 & 0,30 & Valid \\
\hline & $Y_{.4}$ & 0,790 & 0,30 & Valid \\
\hline & $Y_{.5}$ & 0,862 & 0,30 & Valid \\
\hline & $Y_{.6}$ & 0,936 & 0,30 & Valid \\
\hline & $\mathrm{Y}_{.7}$ & 0,936 & 0,30 & Valid \\
\hline & $Y_{.8}$ & 0,722 & 0,30 & Valid \\
\hline
\end{tabular}

Sumber: Data diolah, 2019

Hasil uji validitas pada Tabel 4. menunjukkan bahwa seluruh instrumen penelitian yang digunakan untuk mengukur variabel stres kerja, kepuasan kerja, kompensasi finansial, dan kinerja karyawan memiliki nilai koefisien korelasi dengan skor total seluruh item pernyataan lebih besar dari 0,30. Hal ini menunjukkan bahwa butir-butir pernyataan dalam instrument penelitian tersebut valid dan layak digunakan sebagai instrument penelitian.

Uji realibilitas bertujuan untuk mencari tahu sampai mana konsistensi alat ukur yang digunakan, sehingga bila alat ukur tersebut digunakan kembali untuk meneliti objek yang sama dengan teknik yang sama walaupun waktunya berbeda, maka hasil yang akan diperoleh akan sama. Uji realibilitas mampu menunjukkan sejauh mana instruen dapat dipercaya dan diharapkan. Nilai suatu instrument dapat dikatakan reliable bila nilai Alpha Cronboach $\geq 0,6$. 
Tabel 5.

Rekapitulasi Hasil Uji Reliabilitas Instrumen Penelitian

\begin{tabular}{clcc}
\hline No. & \multicolumn{1}{c}{ Variabel } & $\begin{array}{c}\text { Cronbach's } \\
\text { Alpha }\end{array}$ & Keterangan \\
\hline 1 & Stres Kerja $\left(\mathrm{X}_{1}\right)$ & 0,895 & Reliabel \\
2 & Kepuasan Kerja $\left(\mathrm{X}_{2}\right)$ & 0,877 & Reliabel \\
3 & Kompensasi Finansial $\left(\mathrm{X}_{3}\right)$ & 0,873 & Reliabel \\
4 & Kinerja Karyawan $(\mathrm{Y})$ & 0,922 & Reliabel \\
\hline
\end{tabular}

Sumber: Data diolah, 2019

Hasil uji reliabilitas yang disajikan dalam Tabel 5. menunjukkan bahwa seluruh instrumen penelitian (stress kerja, kepuasan kerja, kompensasi finansial dan kinerja karyawan) menunjukkan tingkat reliabilitas yang baik (koefisien Cronbach's Alpha lebih dari 0,60). Dengan demikian instrument penelitian (kuesioner) dapat digunakan dan di distribusikan ke seluruh target sampel yang telah ditentukan dalam penelitian ini.

Model analisis regresi linier berganda digunakan untuk mendapat koefisien regresi yang akan menentukan apakah hipotesis yang dibuat akan diterima atau ditolak. Hasil analisis regresi linier berganda tercantum pada Tabel 6.

Tabel 6.

Hasil Analisis Regresi Linier Berganda

\begin{tabular}{|c|c|c|c|c|c|c|}
\hline & & Co & ficients $^{\mathrm{a}}$ & & & \\
\hline & & $\begin{array}{r}\text { Unstand } \\
\text { Coeffi }\end{array}$ & $\begin{array}{l}\text { dized } \\
\text { ents }\end{array}$ & $\begin{array}{l}\text { Standardized } \\
\text { Coefficients }\end{array}$ & & \\
\hline & & B & $\begin{array}{l}\text { Std. } \\
\text { Error }\end{array}$ & Beta & $\mathbf{T}$ & Sig. \\
\hline 1 & (Constant) & 12.583 & 2.367 & & 5.315 & .000 \\
\hline & Stres Kerja & -.203 & .089 & -.156 & -2.265 & .026 \\
\hline & Kepuasan Kerja & .824 & .079 & .698 & 10.501 & .000 \\
\hline & $\begin{array}{l}\text { Kompensasi } \\
\text { Finansial }\end{array}$ & .335 & .102 & .229 & 3.298 & .001 \\
\hline $\mathrm{R}$ & & 0,758 & & & & \\
\hline & & 0,575 & & & & \\
\hline & R Square & 0,562 & & & & \\
\hline & & 44,573 & & & & \\
\hline $\mathrm{S}$ & & 0,000 & & & & \\
\hline
\end{tabular}

Sumber: Data diolah, 2019

Berdasarkan Tabel 6. dapat dibuat persamaan regresi linier berganda berikut:

$$
Y=12,583-0,203 X_{1}+0,824 X_{2}+0,335 X_{3}
$$

Keterangan :

$\mathrm{Y} \quad=$ Kinerja Karyawan

$\mathrm{X}_{1} \quad=$ Stres Kerja

$\mathrm{X}_{2} \quad=$ Kepuasan Kerja

$\mathrm{X}_{3}=$ Kompensasi Finansial 
Konstanta $(\alpha)$ sebesar 12,583 memiliki arti apabila stress kerja, kepuasan kerja, dan kompensasi finansial memiliki nilai konstan pada angka nol maka nilai kinerja karyawan akan bernilai sebesar 12,583.

Koefisien regresi variabel stress kerja sebesar 0,203 bernilai negative memiliki arti apabila kepuasan kerja dan kompensasi finansial bernilai 1 satuan maka kinerja karyawan akan semakin menurun sebesar 0,203 dengan asumsi variabel lainnya konstan pada angka nol.

Koefisien regresi variabel kepuasan kerja sebesar 0,824 bernilai positif memiliki arti apabila stress kerja dan kompensasi finansial bernilai 1 satuan maka kinerja karyawan akan meningkat sebesar 0,824 dengan asumsi variabel lainnya konstan pada angka nol.

Koefisien regresi variabel kompensasi finansial sebesar 0,335 bernilai positif memiliki arti apabila stress kerja, kepuasan kerja bernilai 1 satuan maka kinerja karyawan akan meningkat sebesar 0,335 dengan asumsi variabel lainnya konstan pada angka nol.

Uji normalitas adalah untuk menguji model regresi yang dibuat berdistribusi normal atau tidak. Model regresi yang baik adalah memiliki distribusi residual yang normal atau setidaknya mendekati normal. Apabila tidak normal maka akan memberikan hasil prediksi bias.

Tabel 7.

Hasil Uji Normalitas

\begin{tabular}{llr}
\hline & One-Sample Kolmogorov-Smirnov Test & \\
\hline & & $\begin{array}{c}\text { Unstandardized } \\
\text { Residual }\end{array}$ \\
$\mathbf{N}$ & & $\mathbf{1 0 3}$ \\
\hline Normal Parameters ${ }^{\mathrm{a}, \mathrm{b}}$ & Mean & .0000000 \\
& Std. Deviation & 2.76548197 \\
Most Extreme Differences & Absolute & .076 \\
& Positive & .072 \\
& Negative & -.076 \\
Test Statistic & & .076 \\
Asymp. Sig. (2-tailed) & & $.163^{\mathrm{c}}$ \\
\hline Sumber: Data diolah, 2019 & &
\end{tabular}

Berdasarkan uji normalitas dengan menggunakan One-Sampe KolmogorovSmirnov Test yang ditampilkan pada Tabel 7 tersebt menunjukkan bahwa nilai signifikansi dengan menggunakan uji Asymp. Sig. (2-tailed) sebesar 0,076>0,05 maka $\mathrm{H}_{0}$ diterima yang mengindikasikan bahwa data yang digunakan pada penelitian ini terdistribusi normal sehingga dapat disimpulkan bahwa model memenuhi asumsi normalitas.

Uji multikolinearitas bertujuan untuk menguji model regresi ditemukan adanya korelasi antar variabel bebas. Model regresi yang baik seharusnya tidak terjadi korelasi diantara variabel bebas atau dapat dikatakan pula bebas dari multikolinier. Untuk mendeteksi ada atau tidaknya multikoliniearitas dapat dilihat dari nilai Varience Inflation Factor $(V I F)<10$ dan mempunyai nilai tolerance $>$ 0,10. Adapun nilai tolerance dan nilai VIF ditunjukkan pada Tabel 8. berikut: 
Tabel 8.

Hasil Uji Multikolinieritas

\begin{tabular}{llcr}
\hline \multicolumn{3}{c}{ Coefficients $^{\mathbf{a}}$} & \\
\hline & & \multicolumn{3}{c}{ Collinearity Statistics } \\
Model & & Tolerance & VIF \\
1 & Stres Kerja & .909 & 1.100 \\
& Kepuasan Kerja & .972 & 1.028 \\
& Kompensasi Finansial & .892 & 1.121 \\
\hline \multicolumn{2}{l}{ Sumber: Data diolah, 2019 } & &
\end{tabular}

Berdasarkan hasil uji pada tabel 8 dapat diketahui bahwa nilai tolerance untuk variabel stress kerja sebesar 0,909 $(0,909>0,1)$ dengan nilai VIF sebesar 1,100 $(1,100<10)$, nilai tolerance untuk variabel kepuasan kerja sebesar 0,972 $(0,972>$ $0,1)$ dengan nilai VIF sebesar $1,028(1,028<10)$, dan nilai tolerance untuk variabel kompensasi finansial sebesar 0,892 $(0,892>0,1)$ dengan nilai VIF sebesar 1,121 $(1,121<10)$. Semua variabel pada model regresi berganda tersebut memiliki nilai tolerance lebih besar dari 0,1 dan nilai VIF lebih kecil dari 10 maka dapat disimpulkan bahwa model regresi yang digunakan bebas multikolinieritas.

Tujuan dari uji heterokedastisitas adalah untuk menguji apakah model regresi terjadi ketidaksamaan varians dari residual satu pengamatan yang lain. Model regresi yang baik adalah tidak mengundang gejala heterokedastisitas maka akan memberikan prediksi menyimpang.

Tabel 9.

Hasil Uji Heteroskedastisitas

\begin{tabular}{|c|c|c|c|c|c|c|}
\hline \multirow[b]{2}{*}{ Model } & & \multicolumn{2}{|c|}{$\begin{array}{l}\text { Unstandardized } \\
\text { Coefficients }\end{array}$} & \multirow{2}{*}{$\begin{array}{c}\text { Standardized } \\
\text { Coefficients } \\
\text { Beta }\end{array}$} & \multirow[b]{2}{*}{$\mathbf{T}$} & \multirow[b]{2}{*}{ Sig. } \\
\hline & & B & Std. Error & & & \\
\hline 1 & (Constant) & 2.519 & 1.503 & & 1.676 & .097 \\
\hline & Stres Kerja & .091 & .057 & .165 & 1.604 & .112 \\
\hline & Kepuasan Kerja & -.083 & .050 & -.165 & -1.661 & .100 \\
\hline & $\begin{array}{l}\text { Kompensasi } \\
\text { Finansial }\end{array}$ & -.034 & .064 & -.054 & -.523 & .602 \\
\hline
\end{tabular}

Berdasarkan Tabel 9. diatas dapat dilihat bahwa nilai signifikan untuk variabel stres kerja sebesar $0,112(0,112>0,05)$, nilai signifikan untuk variabel kepuasan kerja sebesar $0,100(0,100>0,05)$, dan nilai signifikan untuk variabel kepuasan finansial sebesar 0,602 $(0,602>0,05)$. Semua variabel bebas memiliki nilai signifikansi $>0,05$, maka tidak terjadi heteroskedastisitas pada model regresi. Hasil uji heteroskedastisitas juga dapat dilihat dari grafik scatterplots seperti dibawah ini.

Koefisien determinasi $\left(\mathrm{R}^{2}\right)$ berguna untuk mengukur besarnya kontribusi variabel bebas (stres kerja, kepuasan kerja dan kompensasi finansial) terhadap variabel terikat (kinerja karyawan). Pengujian koefisien determinasi pada penelitian ini akan menggunakan bantuan program SPSS. 
Tabel 10.

Hasil Analisis Koefisien Determinasi

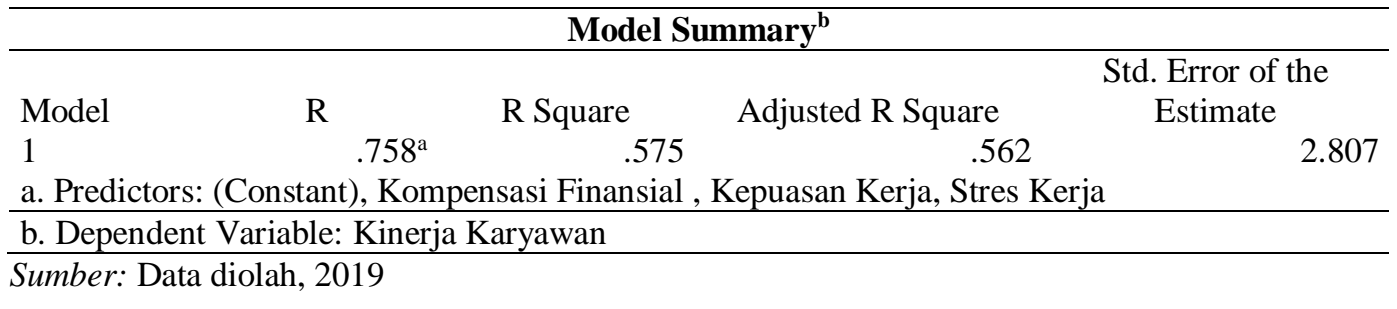

Berdasarkan Tabel 10. dapat diamati nilai adjusted $\mathrm{R}^{2}$ sebesar 0,562. Adapun analisis menggunakan rumus sebagai berikut:
$\mathrm{D}=\mathrm{x} 100 \%$
$\mathrm{D}=0,562 \times 100 \%$
$\mathrm{D} \quad=56,2 \%$

Berdasarkan hasil tersebut berarti 56,2\% perubahan (naik turun) pada kinerja karyawan yang dipengaruhi oleh stress kerja, kepuasan kerja, dan kompensasi finansial, sementara sisanya sejumlah 47,8\% dipengaruhi oleh faktor - faktor lain diluar penelitian ini

Uji simultan (F Test) digunakan untuk mengtahui apakah secara simultan seluruh variable bebas (stres kerja (X1), kepuasan kerja (X2) dan kompensasi finansial (X3) secara serempak terhadap variabel terikat kinerja karyawan (Y). Tabel 11 menunjukkan hasil perhitungan uji simultan F-Test sebagai berikut:

Tabel 11.

Hasil Uji F-test

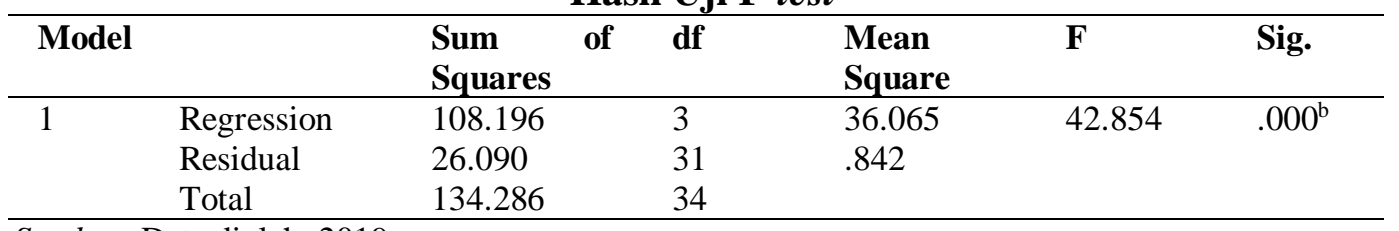

Sumber: Data diolah, 2019

Berdasarkan Tabel 11. hasil uji signifikansi simultan (Uji F) diperoleh nilai signifikansi $\mathrm{F}$ sebesar 0,000. Nilai signifikan 0,000 $<0,05$ mempunyai arti bahwa Motivasi, Kompensasi, dan Disiplin kerja diduga secara signifikan berhubungan dengan Produktivitas kerja

Pengujian secara parsial bertujuan menguji signifikan pengaruh variabel bebas stres kerja, kepuasan kerja dan kompensasi finansial terhadap variabel terikat kinerja karyawan. Tabel 12 menunjukkan hasil perhitungan uji t sebagai berikut: 
Tabel 12.

Hasil Uji t-test

\begin{tabular}{|c|c|c|c|c|c|c|}
\hline \multirow{5}{*}{$\begin{array}{l}\text { Model } \\
1\end{array}$} & \multirow[b]{2}{*}{ (Constant) } & \multicolumn{2}{|c|}{$\begin{array}{l}\text { Unstandardized } \\
\text { Coefficients }\end{array}$} & \multicolumn{3}{|l|}{$\begin{array}{l}\text { Standardized } \\
\text { Coefficients }\end{array}$} \\
\hline & & $\begin{array}{l}\text { B } \\
12.583\end{array}$ & $\begin{array}{l}\text { Std. } \\
\text { Error } \\
2.367\end{array}$ & Beta & $\begin{array}{l}\mathrm{t} \\
5.315\end{array}$ & $\begin{array}{l}\text { Sig. } \\
.000\end{array}$ \\
\hline & Stres Kerja & -.203 & .089 & -.156 & -2.265 & .026 \\
\hline & Kepuasan Kerja & .824 & .079 & .698 & 10.501 & .000 \\
\hline & Kompensasi Finansial & .335 & .102 & .229 & 3.298 & .001 \\
\hline a. $\mathrm{De}_{\mathrm{I}}$ & dent Variable: Kinerja K & aryawan & & & & \\
\hline
\end{tabular}

Sumber: Data diolah, 2019

Berdasarkan hasil uji t pengaruh stress kerja terhadap kinerja karyawan diperoleh nilai signifikansi sebesar 0,026 dengan nilai koefisien regresi sebesar 0,203 bernilai negatif. Nilai signifikansi $0,026<0,05$ mengindikasikan bahwa $\mathrm{H}_{1}$ diterima. Hasil ini mempunyai arti bahwa stress kerja diduga secara signifikan berhubungan negative dengan kinerja karyawan. Hal ini berarti jika stress kerja semakin tinggi, maka kinerja karyawan semakin rendah, sebaliknya jika stress kerja semakin rendah maka kinerja karyawan akan semakin tinggi pula.

Dar et al. (2011) menyatakan bahwa stes kerja berpengaruh negatif terhadap kinerja. Hal ini menunjukkan bahwa semakin tinggi stres kerja yang dirasakan oleh karyawan, menyebabkan penurunan kinerja. Noermijati (2017) menyatakan, stres kerja berpengaruh negatif signifikan terhadap kinerja karyawan. Hasil penelitian ini diperkuat oleh pernyataan Kotteeswari \& Sharief (2014), bahwa ada pengaruh negatif pada stres kerja terhadap kinerja karyawan. Adapun penelitian yang dilakukan oleh Warraich et al. (2014) menyatakan bahwa stress kerja berpengaruh negatif terhadap kinerja karyawan pada Universities of Karachi Pakistan. Hasil penelitian Kanaka (2019) menunjukkan bahwa stres kerja memiliki efek negatif dan signifikan terhadap kinerja pengguna barang. Alam et al. (2015) menyatakan bahwa stres kerja berpengaruh negatif terhadap kinerja karyawan Perbankan Sektor di Khyber Pakhtunkwa Pakistan. Jehangir et al. (2011) stres kerja memiliki korelasi negatif dengan kinerja pekerjaan. Hasil penelitian Olusegun et al. (2014) juga menyatakan juga bahwa stres kerja berpengaruh negative dan signifikan terhadap kinerja karyawan. Kemudian dalam penelitian lain dengan peneliti Putra \& Rahyuda (2015) menyatakan bahwa ada efek negatif dari stres kerja terhadap kinerja. Ahmed \& Ramzan (2013) menyatakan antara stres kerja dan prestasi kerja berkorelasi negatif.

Berdasarkan hasil uji t pengaruh kepuasan kerja terhadap kinerja karyawan diperoleh nilai signifikansi sebesar 0,000 dengan nilai koefisien regresi sebesar 0,824 bernilai positif. Nilai signifikansi $0,000<0,05$ mengindikasikan bahwa $\mathrm{H}_{1}$ diterima. Hasil ini mempunyai arti bahwa kepuasan kerja diduga secara signifikan berhubungan dengan kinerja karyawan. . Kepuasan kerja mensyaratkan bahwa jika 
seseorang melakukan aktivitas kerja sangat baik maka upayanya harus dihargai. Sowmya \& Panchanatham (2011) menyatakan kepuasan kerja adalah suatu keadaan karyawan merasa puas terhadap pekerjaannya. Orang yang mengungkapkan kepuasaan yang tinggi dalam pekerjaannya cenderung lebih produktif, mempunyai keterlibatan yang tinggi dan kecil kemungkinannya dalam mengundurkan diri dibandingkan dengan karyawan yang merasakan kepuasaan kerja yang kurang. Hal ini berarti jika kepuasan kerja semakin baik, maka kinerja karyawan semakin baik, sebaliknya jika kepuasan kerja semakin buruk maka kinerja karyawan akan semakin buruk pula.

Karyawan yang puas memiliki sikap positif tentang pekerjaan mereka. Beberapa penelitian mengemukakan bahwa kepuasan kerja memiliki pengaruh positif dan signifikan terhadap kinerja karyawan yang berarti bahwa rasa kepuasan kerja yang dimiliki pekerja membuat pekerja untuk meningkatkan kinerjanya (Wijayanti \& Subudi, 2014). Dinoka et al. (2014) sebelumnya telah melaporkan bahwa kepuasan kerja memiliki hubungan yang signifikan dengan kinerja kerja karyawan di berbagai sektor bisnis. Prawira \& Suwandana (2019) menyatakan bahwa kepuasan kerja berpengaruh postif dan signifikan terhadap kinerja. Shahzad et al. (2013) dalam penelitianya menyatakan ada korelasi positif antara kepuasan kerja dan kinerja organisasi. Kepuasan kerja memiliki pengaruh yang signifikan terhadap kinerja karyawan (Nazariadli, 2017). Kepuasan kerja juga memberikan pengaruh yang lebih baik kepada kinerja karyawan (Issac, 2017).

Ujianto \& Suhermin (2018) dalam penelitianya yang berjudul Effect of work stress and role conflict on job satisfaction, burn out and performance of female nurses in the sawerigading palopo public hospital menyatakan kepuasan kerja secara positif memberikan dampak pada prestasi kerja perawat perempuan di Rumah Sakit Sawerigading Palopo Umum. Ini berarti bahwa pada tingkat yang lebih tinggi kepuasan kerja akan meningkatkan kinerja pekerjaan perawat perempuan.

Berdasarkan hasil uji t pengaruh kompensasi finansial terhadap kinerja karyawan diperoleh nilai signifikansi sebesar 0,001 dengan nilai koefisien regresi sebesar 0,335 bernilai positif. Nilai signifikansi $0,001<0,05$ mengindikasikan bahwa $\mathrm{H}_{1}$ diterima. . Seseorang bekerja dalam suatu perusahaan untuk memperoleh imbalan atau balas jasa untuk dapat memenuhi kebutuhan hidupnya, oleh karena itu perusahaan memberikan penghargaan dengan jalan memberikan kompensasi bagi karyawannya. Hasil ini mempunyai arti bahwa kompensasi finansial diduga secara signifikan berhubungan dengan kinerja karyawan. Hal ini berarti jika kompensasi finansial semakin baik, maka kinerja karyawan semakin baik, sebaliknya jika kompensasi finansial semakin buruk maka kinerja karyawan akan semakin buruk pula.

Darmawan (2018) menayatakan bahwa, variabel kompensasi finansial secara parsial berpengaruh signifikan terhadap kinerja karyawan. Etebu (2016) menyatakan terdapat pengaruh signifikan antara kompensasi finansial dengan kinerja karyawan. Hasil penelitian Fredriksz (2017) menunjukkan bahwa kompensasi finansial berpengaruh positif dan signifikan terhadap kinerja karyawan. Hal ini menunjukkan bahwa semakin tinggi kompensasi finansial yang diberikan oleh perusahaan, menyebabkan peningkatan kinerja karyawan. Baharuddin et al. 
(2012) menyatakan pula bahwa kompensasi memiliki pengaruh positif signfikan terhadap kinerja. Sementara itu, Nurjahjani (2012) di penelitiannya yang berjudul "pengaruh imbalan finansial terhadap prestasi kerja" menyatakan bahwa kompensasi finansial berpengaruh signifikan terhadap kinerja karyawan departemen pemasaran Jiwa Asih Bumi Jaya Branch Malang. Kompensasi finansial juga berpengaruh positif dan signifikan terhadap kinerja karyawan (Siagian et al., 2018). Hal ini didukung dari penelitian Siregar (2011) dan Muguongo et al. (2015) yang menyatakan bahwa kompensasi finansial berpengaruh positif dansignifikan terhadap kepuasan kerja. Tingkir (2015) menyatakan kompensasi finansial memiliki pengaruh signifikan terhaadap kinerja.

Berdasarkan pemaparan dapat dinyatakan bahwa Stress kerja secara signifikan berpengaruh negatif dengan kinerja karyawan. Hal tersebut berimplikasi bahawa untuk meningkatkan kinerja karyawan pihak manajemen perusahaan hendaknya mengurangi jam kerja sesuai aturan yang berlaku sesuai dengan undang - undang ketenaga kerjaan. Selain itu, pihak manajemen perusahaan hendaknya tidak memberikan tanggung jawab yang tidak sesuai dengan jabatan serta deskripsi pekerjaan yang diemban karyawan.

Selain itu, Kepuasan kerja secara signifikan berpengaruh positif dengan kinerja karyawan. Hasil tersebut mengimplikasikan bahwa pihak manajemen hendaknya mengkondisikan kepuasan kerja karyawan tetap maksimal. Hal tersebut dapat dilakukan dengan cara merancang lingkungan kerja yang mendukung serta menerapkan kebijakan agar karyawan antar satu dengan yang lain dapat memberikan dukungan.

Kompesasi finansial secara signifikan berpengaruh positif dengan kinerja karyawan. Hasil tersebut mengimplikasikan bahwa agar kinerja karyawan optimal maka pihak manajemen perusahaan hendaknya memberikan kompensasi finansial yang sesuai dengan beban kerja serta keuntungan yang diperoleh perusahaan. Selain itu, pihak manajemen hendaknya memberikan insentif yang sesuai dengan kinerja karyawan.

Berdasarkan pemaparan di atas, maka dalam penelitian ini masih terdapat beberapa keterbasan. Pertama, sampel yang dipakai perlu ditingkatkan. Hal tersebut dilakukan bahwa agar hasil yang didapat dapat menggambarkan keadaan dilapangan secara holistic. Kedua, kontruksi variabel yang digunakan pada model penelitian sederhana. Hal tersebut kedepanya dapat ditanggulangi dengan cara menambah kontruksi variabel dalam bentuk variabel mediasi maupun moderasi dan yang terakhir adalah subjektifitas responden terhadap pernyataan yang diberikan didalam kuesioner.

\section{SIMPULAN}

Stres kerja secara signifikan berhubungan negatif dengan kinerja karyawan. Kepuasan kerja secara signifikan berhubungan dengan kinerja karyawan. Kompensasi finansial secara signifikan berhubungan dengan kinerja karyawan.

Bagi Mahasiswa, hasil penelitian ini dapat dijadikan sebagai sumber kajian pustaka dalam melakukan replikasi penelitian sejenis dengan menambah sampel serta merekontruksi model penelitian melalui kombinasi variabel baru yang 
berpeluang memilki pengaruh terhadap kinerja karyawan. Sehingga hasil yang diperoleh dapat menginterpretasikan keadaan yang sebenarnya.

\section{REFERENSI}

Ahmed, A., \& Ramzan, M. (2013). Effects of Job Stress on Employees Job Performance A Study on Banking Sector of Pakistan. Journal of Business and Management, 1(6), 61-68.

Alam, A., \& Shah, S. Z. A. (2013). Corporate Governance and its Impact on Firm Risk. International Journal of Management, Economics and Social Sciences, 2(2), $76-98$.

Alam, Z., Saeed, G., \& Rehman, S. (2015). The Impact of Job Stress on Employee's Performance: Investigating The Moderating Effect of Employees Motivation. City University Research Journal, 5(1), 120-129.

Aprijon. (2014). Pengaruh Kompensasi Terhadap Kinerja Guru SLTA. Jurnal Kewirausahaan, 13(1), 88-101.

Baharuddin, A., Alhabsji, T., \& Utami, H. N. (2012). Pengaruh Pelatihan, Kompensasi dan Disiplin. Kerja terhadap Prestasi kerja Karyawan (Studi Pada Kantor PT. PLN (Persero) Area Pelayanan dan Jaringan Malang). Jurnal Administrasi Bisnis, 6(2).

Charisma, D. C. N., Bagia, I. W., \& Susila, G. P. A. J. (2014). Pengaruh Stres Kerja dan Kepuasan Kerja Terhadap Kinerja Pada Bagian Tenaga Penjualan UD Surya Raditya Negara. Jurnal Manajemen Universitas Pendidikan Ganesha, 2 .

Dar, L., Akmal, A., Naseem, M. A., \& Khan, K. U. D. (2011). Impact of Stress on Employees Job Performance in Business Sector of Pakistan. Global Journal of Management and Business, 11(6), 1-4.

Darmawan, P. (2018). Effect of Employee Integrity and Financial Compensation to Employee Performance in Education and Educational Leadership at East Java Provincial Training and Education Agency. Int. J. Adv. Res, 6(7), 335-340.

Dinoka, G. N. P., Khatibi, A., Navaratna, N., \& Chinna, K. (2014). Job satisfaction and job performance among factory Employees in apparel sector. Asian Journal of Management Sciences \& Education, 3(1).

Etebu, C. (2016). Financial Compensation and Employee Performance of Bayelsa State Civil Service. Journal of Resources Development and Management, 11, $1-6$. 
Firmansah, M. I., \& Santy, R. D. (2011). Pengaruh Iklim Organisasi dan Karakteristik Pekerjaan Terhadap Kepuasan Kerja Karyawan di Lingkungan Pemerintah Daerah Kabupaten Sukabumi. Majalah Ilmiah Unikom, 6(2), 225-232.

Fredriksz, G. (2017). Pengaruh Kompensasi Finansial dan Kompensasi Nonfinansial terhadap Kinerja Karyawan. Jurnal Penelitian Manajemen Terapan (PENATARAN), 2(2), 143-15.

Google. (2019). Watersport Tanjung Benoa Bali.

Halkos, G., \& Bousinakis, D. (2010). The effect of stress and satisfaction on productivity. International Journal of Productivity and Performance Management, 59(5), 415-431. https://doi.org/https://doi.org/10.1108/17410401011052869

Hanim, M. (2016). Pengaruh Stres Kerja Terhadap kepuasan Kerja Serta Dampaknya pada Kinerja Karyawan. Jurnal Ilmu Manajemen, 4(3).

Harianto, F., Wiguna, P. A., \& Rakhmad, D. (2008). Pengaruh Stres Kerja, dan Gaya Kepemimpinan terhadap Kinerja Tenaga Kerja Pada Proyek Mall Yani Golf di Surabaya. Jurnal Iptek, 11(3), 139-145.

Hermawati, A. (2012). Pengaruh Motivasi dan Kemampuan terhadap Prestaasi Kerja Pegawai Dinas Pendidikan Pemerintah Kota Batu. Jurnal Dinamika Dotcom, 3(2), 107-120.

Issac, S. S. (2017). Divulging The Teachers Job Satisfaction Effect on Better Work Performance. International Journal of Mechanical Engineering and Technology (IJMET), 8(3), 279-290.

Jehangir, M., Kareem, N., Khan, A., Jan, M. T., \& Soherwardi, S. (2011). Effect of job stress on job performance and job satisfaction. Interdisciplinary Journal Of Contemporary Research in Bussiness, 3(7), 453-465.

Kaliski, B. S. (2007). Encyclopedia of Business and Finance (Second). Detroit: Thompson Gale.

Kanaka, I. W. G. W. (2019). The effect of job stress and self leadership towards performance of user goods manager in the Bali provincial government with supportive leadership as moderating. International Journal of Economics, Commerce and Management, 7(2), 441-462.

Khan, A. H., Nawaz, M. M., Aleem, M., \& Hamed, W. (2012). Impact of job satisfaction on employee performance: An empiricial study of autonomous Medical Institution of Pakistan. African Journal of Bussines Management, 
6(7), 2697-2705.

Kotteeswari, M., \& Sharief, T. (2014). Job Stress And Its Impact On Performance Employees Working In BPOS. International Journal of Advanced Research in Management, 5(2), 19-27.

Leka, S., Griffiths, A., Cox, T., \& WHO. (2004). Work organisation and stress : systematic problem approaches for employers, managers and trade union representatives / authors: Stavroula Leka, Amanda Griffiths,Tom Cox. World Health Organization.

Logan, M. S., \& Ganster, D. C. (2005). An Experimental Evaluation of a Control Intervention to Alleviate Job-Related Stress. Journal of Management, 31(1). https://doi.org/https://doi.org/10.1177/0149206304271383

Mangkunegara, A. P. (2015). Manajemen Sumber Daya Manusia Perusahaan. Bandung: Remaja Rosdakarya.

Mondy, \& Noe. (2013). Human Resources Management. Jakarta: Salemba Empat.

Muguongo, M. M., Muguna, A. T., \& Muriithi, D. K. (2015). Effects of compensation on job satisfaction Among Secondary School Teachers in Maara Sub - Country of Tharaka Nithi County, Kenya. Journal of Human Resource Management, 3(6), 47-59.

Nazariadli, S. (2017). The Trade-Offs between Job Satisfaction, Performance, and Locus of Control on Job Performance: Case of Sohana Outfitters Company. J Tourism Hospit, an Open Access Journal, 6(1), 231 - 240.

Noermijati, D. P. (2017). The Trade-Offs between Job Satisfaction, Performance, and Locus of Control on Job Performance: Case of Sohana Outfitters Company. J Tourism Hospit, an Open Access Journal, 6(1), 1-6.

Nurjahjani, F. (2012). Pengaruh Imbalan Finansial terhadap Prestasi Kerja. Modernisasi. Jurnal Ekonomi Modernisasi, 3(1).

Olusegun, A. J., Oluwasayo, A. J., \& Olawoyim, O. (2014). An Overview of the Effect of Job Stress on employees Performance in Nigeria Tertiary Hospitals. Scientific Review Article, 60(4), 139-153.

Omotayo, O. A., Pavithra, S., \& Adenike, A. A. (2014). Compensation Management and Organisational Commitment in Developing Economics: Indian Perspective. Acme Intellects International Journal of Reasearch in Management, Social Sciences \& Technnology, 8(8), 1-15.

Prawira, I. G. A. G. Y., \& Suwandana, I. G. M. (2019). Peran Kepuasan Kerja 
Memediasi Pengaruh Stres Kerja Terhadap Kinerja Karyawan Housekeeping Department Fave Hotel. E-Jurnal Manajemen, 8(8), 5060-5089.

Purnomo, H., Hutomo, P. T. P., \& Tysol, J. S. P. (2013). Analisis Pelatihan, Kompensasi, dan Komunikasi terhadap Kepuasan Kerja dan Kinerja Karyawan (Analysis of training, compensation, and communication towards employees' job satisfaction and performance). Jurnal Ilmiah Dinamika Ekonomi Dan Bisnis.

Putra, I. B. K. S. D., \& Rahyuda, A. G. (2015). Pengaruh Lingkungan Kerja Fisik dan Stres Kerja terhadap Kinerja Pegawai di Pengujian Kendaraan Bermotor Dinas Perhubungan Kota Denpasar. E-Jurnal Manajemen Universitas Udayana, 4(9).

Rivai, V. (2006). Manajemen Sumber Daya Manusia untuk Perusahaan : dari Teori Ke Praktik (Pertama). Jakarta: Raja Grafindo Persada.

Robbins, S. P. (2013). Organizational behavior (Fifteenth). New Jersey: Pearson Higher Education.

Shahzad, L. M., Ahmad, M., Qasim, M., Mushtaq, M., Amber Ferdoos, \& Naeem, H. (2013). Impact of employee's job satisfaction on organizational performance. European Journal of Business and Management, 5(5), 166-171.

Siagian, J. A., Falimunthe, R. F., \& Siahaan, E. (2018). The Effect of Financial Compensation, Work and Family Environment on Employee Performance at PT. Bank Sumut Coordinating Branch Medan. International Journal for Innovative Research in Multidisciplinary Field, 4(8), 144-149.

Siregar, E. (2011). Pengaruh motivasi kerja, kinerja individual, dan sistem kompensasi finansial terhadap kepuasan kerja. Jurnal Pendidikan Penabur, $16,81-93$.

Sowmya, K. R., \& Panchanatham, N. (2011). Factors influencing job satisfaction of banking sector employees in Chennai, India. Journal of Law and Conflict Resolution, 3(5), 76-79.

Suparyadi. (2015). Manajemen Sumber Daya Manusia. Jakarta: Andi.

Tantowi, A., Said, L. R., \& Rahmawati, R. (2016). Pengaruh Kompensasi Finansial dan Non Finansial Terhadap Kepuasan Kerja Serta Dampaknya Terhadap Turnover Intention Pada Pelaut di PT. Maritim Barito Perkasa Banjarmasin. Jurnal Wawasan Manajemen, 4(1), 11-25.

Tingkir, M. S. D. (2015). Pengaruh Kompensasi Finansial Dan Non Finansial Terhadap Kinerja Karyawan Pada PT. Bank Prima Master Kantor Pusat 
Surabaya. Agora, 3(2), 16-21.

Torang, S. (2013). Organisasi dan Manajemen (Perilaku, Struktur, Budaya \& Perubahan Organisasi. Bandung: Alfabeta.

Triatna, C. (2015). Perilaku Organisasi. Bandung: Remaja Rosdakarya. Tripadvisor. (2019). Watersport Tanjung Benoa Bali.

Ujianto, N., \& Suhermin. (2018). Effect of work stress and role conflict on job satisfaction, burn out and performance of female nurses in the Sawerigading Palopo public hospital. European Journal of Business and Social Sciences, 6(11), $204-215$.

Velnampy, T., \& Aravinthan, S. (2013). Occupational Stress and Organizational Commitment in Private Banks. A Sri Lanka Experience. Europan Journal of Business and Management, 5(7), 78-99.

Warraich, U. A., Raheem, A. R., Nawaz, A., \& Imamuddin, K. (2014). Impact of Stress on Job Performance: An Empirical Study of the Employees of Private Sector Universities of Karachi, Pakistan. Journal of Management Sciences, 3(7), 14-17.

Wijayanti, N. K. A. L., \& Subudi, M. (2014). Pengaruh Kepemimpinan, Kompensasi Finansial terhadap Kepuasan Kerja Serta Dampaknya terhadap Kinerja Karyawan. E-Jurnal Manajemen Universitas Udayana, 3(11), 33963414.

Wirawan, N. (2002). Cara Mudah Memahami Statistik 2 (Statistik Inferensia) Untuk ekonomi dan Bisnis (Kedua). Denpasar: Keraras Emas.

Yusnimar, M. Y., \& Mahdani. (2015). Influence of organizational culture and work stress on job satisfaction and its impact on the performance of employees of PT. Aceh Bank. Postgraduate Management Journal Syiah Kuala University, 4(1), 135-143.

Zafar, Q., Ali, A., Hameed, T., Ilyas, T., \& Younas, H. I. (2015). The Influence of Job Stress on Employes Perfomance in Pakistan. American Journal of Social Science Research, 1(4), 221-225.

Zainal, V. R., Hadah, M. D., \& Ramly, H. M. (2014). Kepemimpinan dan Perilaku Organisasi (Keempat). Jakarta: Raja Grafindo Persada. 